\title{
EXPERIMENTAL STUDY OF BRAZILIAN TENSILE STRENGTH OF CONCRETE UNDER STATIC LOADS
}

\author{
Rui $\mathrm{Li}^{1}$, Lei Liu ${ }^{1}$, Zhihua Zhang ${ }^{1}$ and Huaming $\mathrm{An}^{2 *}$ \\ ${ }^{1}$ Faculty of Land Resources Engineering, Kunming University of Science and Technology, Kunming, China, 650093 \\ ${ }^{2}$ Faulty Public Security and Emergency Management, Kunming University of Science and Technology, Kunming, China, 650093.
}

\begin{abstract}
Concrete is one of the most significant materials in modern society. It is widely used in many projects. Thus it is essential to study the strength and the failure patterns of this material. As well known, the compressive strength is much higher than the tensile strength for concrete. Thus, it is easy to fail due to the tensile strength for concrete. Thus, this paper focuses on the study of the tensile strength of the concrete and its failure patterns. Three types of concretes are made for studying the tensile strengths and the failure patterns of the concretes. Then the Brazilian tensile strength test method is employed in this study. The mythology of calculating tensile strength by the Brazilian tensile strength test method is introduced. Many discs are made for the tests. The Rock mechanics testing machine is used to excavate pressure on the top and bottom of the disc. It is concluded that the failure of the disc is along the vertical diameter between the top and bottom plates contacting the dis. The tensile failure is not obviously influenced by the ratios of the materials while the tensile strength is significantly influenced by the ratios of the concrete. The damage index of concrete is also proposed to describe the capabilities of resisting failure.
\end{abstract}

\section{Introduction}

The Brazilian Tensile Strength (BTS) Test was originally developed by Akazawa(1943) and Carneiro (1943) independently and the method was developed for calculating the tensile strength $[1,2]$. The stress and strain at any point on the disc during BTS test can be calculated by the equations conducted by Hondors(1959)[3]. The equations then were utilized by some researchers to calibrate their numerical methods [4, 5].Hobbs(1964,1967) studied the relationship of tensile strength and compressive strength for rock using BTS test with a central hole[6, 7]. Griffith-type fracture criterion was used to analyze the BTS test in terms of rock failure[8]. The fracture might not occur from the center of the dis. Yangidani, et al. (1978) [9] had done some tests to study the crack initiation place and they point out the fracture firstly occurs at the tensile zone instead of the loading points. Flattened BTS test was conducted by Wang. Jia et al. (2004) to obtain the elastic modulus, tensile strength[10].

Although many researches have been done in terms of methodology and theory, it is still essential to study the BTS test for many materials, especially for those ingredients can be changed. In this paper, the Brazilian disc test is employed to study the tensile strengths of concrete. The ratios of cement and sand are studied in terms of the influences of the tensile strengths of the concrete. The failure patterns have been obtained. The damage indexes are also discussed.

\section{Methods}

In this paper, the BTS test is conducted to determine the tensile strength of the concrete, since the concrete is brittle material and the conventional methods are not able to cope with this kind materials.

Fig.1 shows the geometrical model of the Brazilian disc tensile strength test. As shown in Fig. 1 two plates are placed between the specimens. The two plates will move toward each other. The loads from the plates could be assumed to be radially applied over a short strip of the circumference with a radian of $2 \alpha$ as shown in Fig. 1.

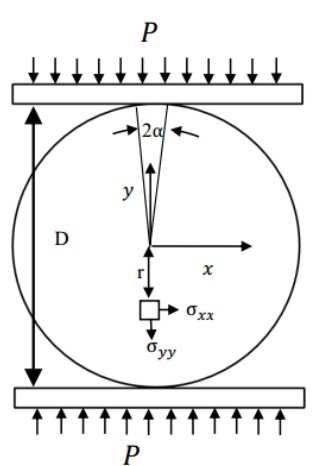

Fig. 1. Geometreical model of the Brazilian tensile strenght test

The equations Hondros (1959) for calculating the stress at any point along the vertical diameter are as follows.

*Corresponding author e-mail: huaming. an@kust.edu.cn (Huaming An) 


$$
\begin{aligned}
& \sigma_{\mathrm{xx}}=\frac{p}{\pi R \operatorname{ta}}\left\{\frac{\left[1-\left(\frac{T}{R}\right)^{2}\right] \sin 2 \alpha}{1-2\left(\frac{T}{R}\right)^{2} \cos 2 \alpha+\left(\frac{T}{R}\right)^{4}}-\tan ^{-1}\left[\frac{1+\left(\frac{T}{R}\right)^{2}}{1-\left(\frac{T}{R}\right)^{2}} \tan (\alpha)\right]\right\} \\
& \sigma_{\mathrm{yy}}=-\frac{p}{\pi R \operatorname{ta} \alpha}\left\{\frac{\left[1-\left(\frac{T}{R}\right)^{2}\right] \sin 2 \alpha}{1-2\left(\frac{T}{R}\right)^{2} \cos 2 \alpha+\left(\frac{T}{R}\right)^{4}}+\tan ^{-1}\left[\frac{1+\left(\frac{T}{R}\right)^{2}}{1-\left(\frac{T}{R}\right)^{2}} \tan \alpha\right]\right\}
\end{aligned}
$$

Where $\mathrm{P}$ is the applied load, $\mathrm{R}$ is the disc radius, $\mathrm{r}$ is the distance from centhe tre of the disc, $\mathrm{t}$ is the disc thickness, $2 \alpha$ is the angular distance of load arc, $\sigma \_x x$ and $\sigma \_y y$ are stresses along the horizontal and vertical directions respectively.

Thus, taking into account the specimen thickness $t$, the tensile strength can be calculated by Eq.3 [12]:

$$
\sigma_{\mathrm{t}}=\frac{2 p}{\pi \mathrm{Dt}}
$$

where the is the tensile strength, is the applied load,is the diameter.

\section{The specimen preparation}

The specimens are made of cement, sand, pebble, and water. Three types of concretes are made and the ratios are shown in Tab.1. The ratios are from the classification by compressive strength for concrete at international standard organization 3839-1977. Thus the number also forms the ISO 3839, which are C25, C35 and C45. C45 is the strongest material in terms of compressive strength while C25 is the weakest one according to the ISO 38391977.

Table 1. Setting Word's margins.

\begin{tabular}{|c|c|c|c|c|}
\hline Number & $C$ ement & Sand & Pebble & Water \\
\hline$C 25$ & 1.540 & 3.770 & 6.350 & 1 \\
\hline$C 35$ & 1.781 & 3.472 & 5.428 & 1 \\
\hline$C 45$ & 2.366 & 2.830 & 5.494 & 1 \\
\hline
\end{tabular}

Table 2. Formatting sections, subsections and subsubsections.

\begin{tabular}{|c|c|c|c|c|c|}
\hline No & $\mathrm{L} / \mathrm{D}$ & $\mathrm{M} / \mathrm{g}$ & $\mathrm{V} / \mathrm{cm}^{3}$ & $\rho / \mathrm{g} \cdot \mathrm{cm}^{-3}$ & $\mathrm{P} / \mathrm{m} \cdot \mathrm{s}^{-1}$ \\
\hline C25-P-1 & 0.485 & 371 & 155.67 & 2.383 & 2800 \\
\hline C25-P-2 & 0.490 & 379 & 159.89 & 2.370 & 2450 \\
\hline C25-P-3 & 0.484 & 353 & 150.21 & 2.350 & 2650 \\
\hline C35-P-1 & 0.530 & 398 & 169.94 & 2.342 & 2892 \\
\hline C35-P-2 & 0.512 & 392 & 165.64 & 2.367 & 2478 \\
\hline C35-P-3 & 0.515 & 381 & 163.86 & 2.325 & 3012 \\
\hline C45-P-1 & 0.494 & 380 & 159.12 & 2.388 & 3000 \\
\hline C45-P-2 & 0.509 & 384 & 161.88 & 2.372 & 2895 \\
\hline C45-P-3 & 0.501 & 390 & 162.25 & 2.404 & 2695 \\
\hline
\end{tabular}

\section{Bazilian tensile strength tests}

As shown in Fig. 2, the concrete disc with an average diameter of $75 \mathrm{CM}$ and thickness of $37.5 \mathrm{~cm}$ is under test by a TAW-2000DRock mechanics testing machine. The Brazilian disc is placed between two plates while the top plate is moving by the constant speed of $0.3 \mathrm{Mpa} / \mathrm{s}$. The top plate will stop moving until the dis lost its capability of carrying the load. The tensile strength or concrete disc can be calculated by Eq. 3 .

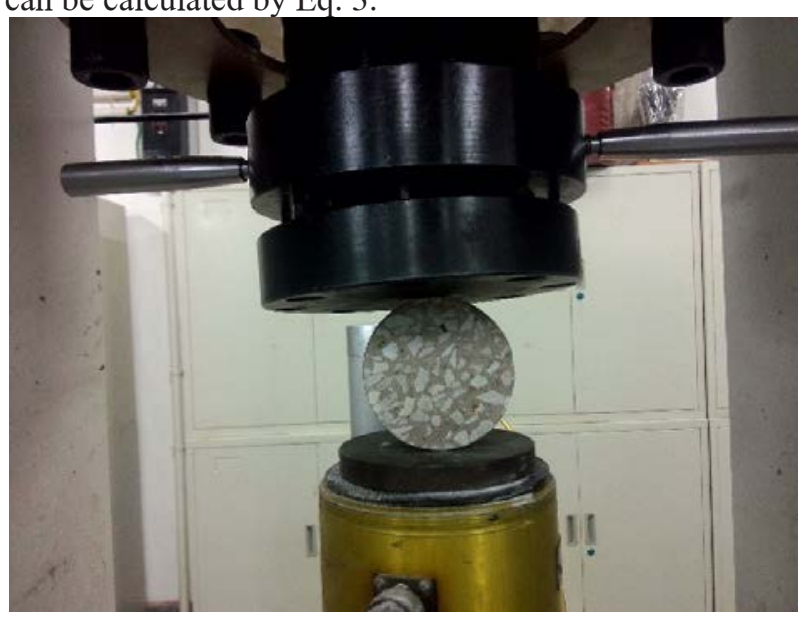

Fig. 2. Concrete disc on test by TAW-2000D Rock mechanics testing machine

Fig. 3, 4 and 5 show the failure patterns of Brazilian tensile strength tests. It can be seen that the failure modes are almost the same. The fracture is almost along the vertical diameter. The disc is separated into two halves. But it seems that for the $\mathrm{C} 25$ disc it was produced more fracture as shown on the left side of the Fig. 3.

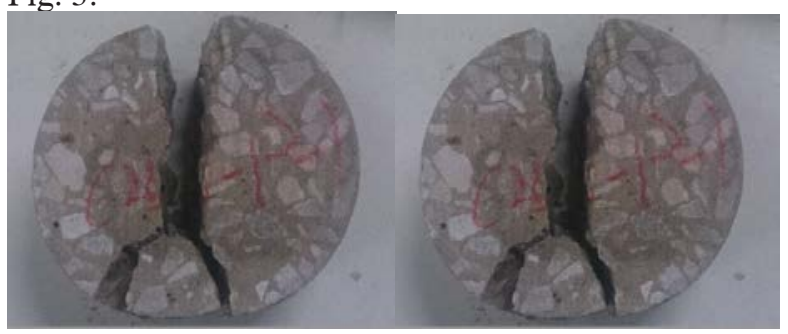

Fig. 3. Failure patterns of concrete dis with materials $\mathrm{C} 25$

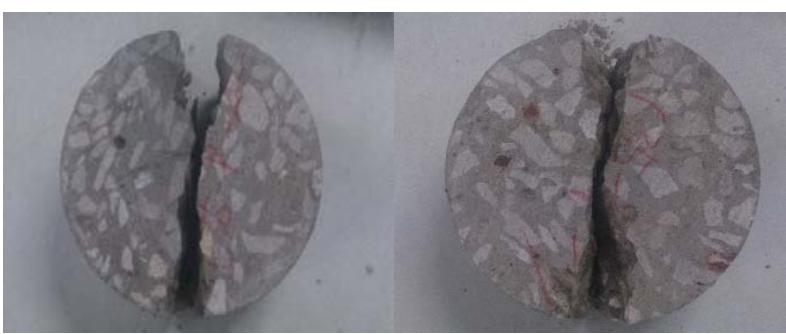

Fig. 4. Failure patterns of concrete dis with materials C35

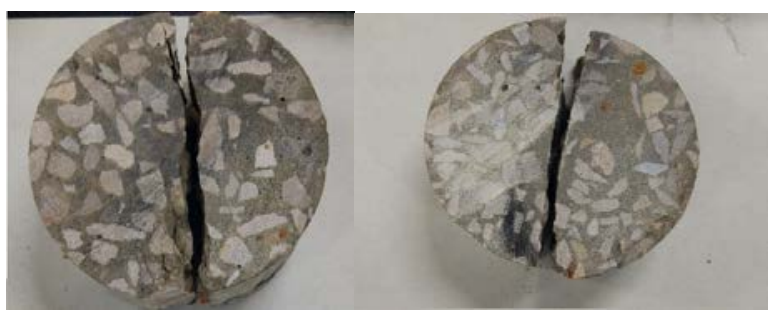

Fig. 5. Failure patterns of concrete dis with materials $\mathrm{C} 45$

Tab. 3 show the experimental results for the Brazilian tensile strength test. The average strength for concrete 
$\mathrm{C} 25, \mathrm{C} 35$ and $\mathrm{C} 45$ are $2.91 \mathrm{Mpa}, 3.43 \mathrm{Mpa}$, and $3.87 \mathrm{MPa}$. It is concluded that $\mathrm{C} 45$ is the strongest material in terms of tensile strength. In addition, the ratios of cement, sand, pebble, and water significantly influence the tensile strength of the concrete. However, the failure patterns of the concrete are not influenced by ratios of the concrete.

Table 3. Three types of speciemen for tensile strenght test

\begin{tabular}{|c|c|c|}
\hline Number & Tensiel Strength & \multirow{2}{*}{ Average } \\
\hline C25-P-1 & 3.13 & \multirow{2}{*}{2.91} \\
\hline C25-P-2 & 2.97 & \\
\hline C25-P-3 & 2.63 & \multirow{2}{*}{3.43} \\
\hline C35-P-1 & 3.29 & \\
\hline C35-P-2 & 3.62 & \multirow{2}{*}{3.87} \\
\hline C35-P-3 & 3.42 & \\
\hline C45-P-1 & 4.08 & \\
\hline C45-P-2 & 3.47 & \\
\hline C45-P-3 & 4.05 & \\
\hline
\end{tabular}

\section{Discussion}

Fig. 6 shows the relationship between the tensile strength of concrete and its ratio of cement. It can be seen that with the increase in the ratio of cement, the tensile strength become stronger and stronger. Thus, the tensile strength of the concrete is significantly influenced by the ratio of cement. But it does not mean the more cement the stronger of the concrete. The ratio of cement, sand, pebble and water must be appropriate and under certain standard.

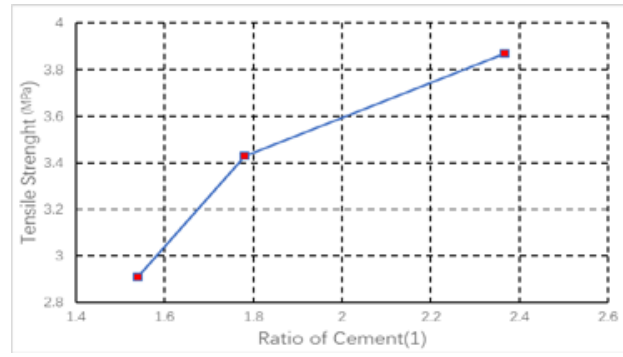

Fig. 6. Tensile strength-Cement ratio Curve

Fig. 7 illustrates the relationship between the tensile strength of the concrete and its ratio of sand. It indicates that with the increase of the sand ratio, the tensile strength decreases. Thus, the ratio of sand plays a critical role in the tensile strength of the concrete.

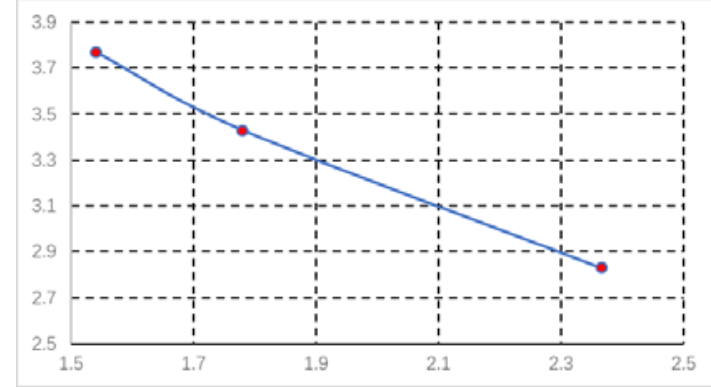

Fig. 7. Tensile strength-Sandratio Curve
In order to compare the strength of the concrete in resisting failure, the damage index is proposed here that can be calculated by Eq. 4 .

$$
\mathrm{K}_{L}=1-\frac{\left(\mathrm{T}_{0}-\mathrm{T}\right)}{\mathrm{T}_{\mathrm{o}}}
$$

where the $\mathrm{Kl}$ is the damage of index for concrete;

$\mathrm{T}$ is the tensile strenght of $\mathrm{C} 45$

$\mathrm{T}$ is the tensile strenght of $\mathrm{C} 35$ or $\mathrm{C} 25$

According to Eq.4, the damage indexes for $\mathrm{C} 35, \mathrm{C} 45$ and $\mathrm{C} 25$ are $100.00 \% 、 88.63 \%, 75.19 \%$ respectively.

Fig. 8 visually shows the damage index of different concretes. The damage of $\mathrm{C} 35$ and $\mathrm{C} 25$ decrease $24.81 \%, 11.37 \%$ compared with C45. Thus C45 is the strongest concrete in terms of resisting concrete failure.

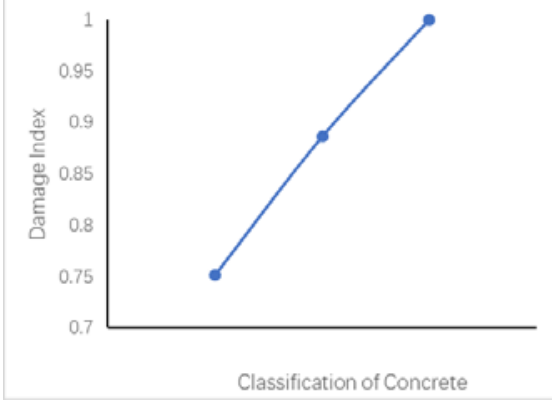

Fig. 8. The damage index-Classification of Concrete Curve

\section{Conclusion}

This paper studies the tensile strength of concrete by experimental method. The concrete specimens are made according to the international standard 3839 for concrete classification by compressive strength. The concrete is made of cement, sand, pebble and water according to ratios from the international standard for concrete making. The tensile failure patterns have been obtained and the tensile strength is obtained. In addition, the influence of the ratio of cement and sands are discussed. Furthermore, the damage index is proposed for describing the concrete character of resisting concrete failure. It is concluded that:

- Brazilian disc can be used to acquire the tensile strength of concrete by excavating compressive stress on the top and bottom of the concrete disc.

- The tensile failure of the concrete occurs along the vertical diameter where the compressive stresses are excavated on the two ends of the disc.

- The tensile strength is significantly influenced by the ratios of the mixed materials for making concrete.

- The damage index of the concrete visually shows the comparison of the three types of concrete in terms of capabilities of carrying loads

\section{Acknowledgments}

This research presented in this study is partly supported by the following foundation and organizations: National science foundation of China (Grant number: 11862010), Program for Innovative Research Team (in Science and Technology) in University of Yunnan Province, Project 
supported by the Scientific Research Fundation of the Education Department of Yunnan (Grant number: 2020Y0088)and Yunnan Key Laboratory of SinoGerman Blue Mining and Utilization of Special Underground Space, which are of greatly appreciated. Moreover, the authors would like to thanks the anonymous reviewers for their valuable comments and constructive suggestion.

\section{References}

1. Akazawa, T., New test method for evaluating internal stress due to compression of concrete (the splitting tension test)(part 1). J Jpn Soc Civ Eng. 29: p. 777-787(1943).

2. Carneiro, F. A new method to determine the tensile strength of concrete. in Proceedings of the 5th meeting of the Brazilian Association for Technical Rules, 3d. Section(1943).

3. Hondros, G., The evaluation of Poisson's ratio and the modulus of materials of a low tensile resistance by the Brazilian (indirect tensile) test with particular reference to concrete. Australian Journal of Applied Science. 10(3): p. 243-268(1959).

4. Zhu, W. and C. Tang, Numerical simulation of Brazilian disk rock failure under static and dynamic loading. International Journal of Rock Mechanics and Mining Sciences. 43(2): p. 236-252(2006).

5. Li, D. and L.N.Y. Wong, The Brazilian disc test for rock mechanics applications: review and new insights. Rock mechanics and rock engineering. 46(2): p. 269-287(2013).

6. Hobbs, D. The tensile strength of rocks. in International Journal of Rock Mechanics and Mining Sciences \& Geomechanics Abstracts. Elsevier(1964).

7. Hobbs, D. Rock tensile strength and its relationship to a number of alternative measures of rock strength. in International Journal of Rock Mechanics and Mining Sciences \& Geomechanics Abstracts. Elsevier(1967).

8. Colback, P. An analysis of brittle fracture initiation and propagation in the Brazilian test. in 1st ISRM Congress. International Society for Rock Mechanics(1966).

9. Yanagidani, T., et al. The observation of cracks propagating in diametrically-compressed rock discs. in International Journal of Rock Mechanics and Mining Sciences \& Geomechanics Abstracts.Elsevier(1978).

10. Wang, Q., et al., The flattened Brazilian disc specimen used for testing elastic modulus, tensile strength and fracture toughness of brittle rocks: analytical and numerical results. International Journal of Rock Mechanics and Mining Sciences. 41(2): p. 245-253(2004).

11. Procopio, A., A. Zavaliangos, and J. Cunningham, Analysis of the diametrical compression test and the applicability to plastically deforming materials.
Journal of Materials Science. 38(17): p. 36293639(2003).

12. Timoshenko, S. and J. Goodier, Theory of Elasticity. McGraw-Hill, New York, NY(1970). 